\title{
EFFECTS OF UNRESTRICTED FEEDING DURING OESTRUS ON REPRODUCTION IN THE UNDERFED FEMALE RAT
}

\author{
K. J. COOPER, N. B. HAYNES ANd G. E. LAMMING \\ University of Nottingham School of Agriculture, \\ Sutton Bonington, Loughborough, Leicestershire
}

(Received 1st July 1969, revised 10th November 1969)

\begin{abstract}
Summary. The reproductive capacity of the female rat as determined by cyclic behaviour, ovulation rate and number of viable foetuses after 19 days of pregnancy has been studied in relation to nutrient intake. Reproductive capacity decreased with increase in the degree of nutrient restriction imposed, but unrestricted feeding for $12 \mathrm{hr}$ immediately before the estimated time of ovulation significantly increased the ovulation rate $(P<0.05)$ though not the number of viable foetuses of underfed rats.
\end{abstract}

\section{INTRODUCTION}

It has been established in the pig that an alteration in dietary regimen can have a significant effect on ovulation rate and embryo survival. Gilts allowed an unrestricted feed intake had a higher number of ovulations than those on a restricted food allowance, but the restricted gilts had a significantly higher proportion of ova shed represented by normal embryos on the 25th day of gestation. This difference was not due to any effect on fertilization rate (Robertson, Casida, Grummer \& Chapman, 1951). A period of unrestricted intake for less than one oestrous cycle was sufficient to increase ovulation rate in gilts compared with restricted controls (Self, Grummer \& Casida, 1955; Zimmerman, Self \& Casida, 1957; Zimmerman, Spies, Self \& Casida, 1960; Rigor, Meyer, First \& Gasida, 1963). Further, it was demonstrated that a short period of extra nutrient intake (ENI) for 1 day following first service in early oestrus would increase both the ovulation rate and litter size of sows and gilts fed a restricted diet (Heap, Lodge \& Lamming, 1967; Lodge \& Hardy, 1968).

In view of the possible economic importance of short term ENI in the gilt resulting in an increase in litter size and the fact that ovulation rate in the rat is also affected by energy restriction (Bellows, Meyer, Hoekstra \& Casida, 1966), the experiments described here were undertaken. They were designed to determine (a) whether a regimen of underfeeding similar to that used for the gilt in commercial practice could be established in the young female rat to exert a significant effect on ovulation rate and embryonic mortality when compared with animals given unlimited access to food and (b) whether such differences could be modified by a short period of increased nutrient allowance before ovulation. 


\section{MATERIALS AND METHODS}

Experiment 1 . The effects of dietary restriction on reproductive function in the female rat Animals. One hundred female rats of Wistar origin (average weight $125 \mathrm{~g}$ ) were used. They had been weaned at 21 days and given unlimited access to the proprietary ration used in the animal colony (Table 1 , diet A). The experiment started when rats were 12 weeks of age and had completed at least two normal oestrous cycles of 4 to 5 days (as determined by vaginal smears taken daily at 11.00 hours).

Experimental design. The animals were caged individually under a lighting regimen of $12 \mathrm{hr}$ light $/ 12 \mathrm{hr}$ dark and a temperature of approximately $70^{\circ} \mathrm{F}$ and allocated randomly to five equal groups (random number tables were used throughout all experiments). Each group received a different feed level at 14.00 hours each day as follows: one group was fed without restriction and the daily mean intake recorded (the average unrestricted intake throughout all experiments was $13.98 \pm 0.2 \mathrm{~g} /$ day). The remaining groups were given restricted diets of $75,62 \cdot 5,50$ and $35 \%$ by weight in grams of the mean daily unrestricted food intake. The supplement of the proprietary ration (Table 1, $\operatorname{diet} A$ ) was

TABLE 1

COMPOSITION OF THE DIETS

\begin{tabular}{lr|lr}
\hline \multicolumn{1}{c|}{ Diet $A$} & & \multicolumn{1}{c}{ Diet B } \\
\hline Barley meal & $50 \mathrm{~g}$ & Barley meal & $40 \mathrm{~g}$ \\
Wheat meal & $20 \mathrm{~g}$ & Wheat meal & $50 \mathrm{~g}$ \\
Millers wheat offals & $20 \mathrm{~g}$ & White fishmeal & $10 \mathrm{~g}$ \\
White fishmeal & $5 \mathrm{~g}$ & Supplemented with cod liver oil (1 gall/ton of feed) \\
Soyabean meal & $5 \mathrm{~g}$ & plus mineral/vitamin supplement $\dagger$ & \\
Plus mineral/vitamin supplement* & & & \\
\hline
\end{tabular}

* Supplement provides for unrestricted animals/kg diet: $\mathrm{Ca}, 3.2 \mathrm{~g} ; \mathrm{P}, 0.55 \mathrm{~g} ; \mathrm{NaCl}, 2.2 \mathrm{~g} ; \mathrm{Fe}, 352 \mathrm{mg}$; $\mathrm{Mn}, 10 \mathrm{mg}$; Cu, 5.9 mg; Co, $11 \mathrm{mg}$; I, $2.6 \mathrm{mg} ; \mathrm{Zn}, 100 \mathrm{mg}$; vitamin A, 3960 i.u.; vitamin $\mathrm{D}_{3}, 990$ i.u.; vitamin $\mathrm{B}_{2}, 1.5 \mathrm{mg}$.

$\dagger$ As for Diet A except vitamin $A, 7920$ i.u.; vitamin $D_{3}, 1800$ i.u.; vitamin $B_{2}, 2.4$ mg.

adjusted so that all groups of animals received the same daily intake of minerals and vitamins in order to avoid possible complications of reproductive malfunction due to mineral and vitamin deficiency. Continuous access to water was provided. Daily weighings and vaginal smears of all animals were taken throughout the experiment. With the exception of the $35 \%$ group, animals were maintained on the restricted diet for a period of at least 28 days before mating. All animals of the $35 \%$ group showed no vaginal cyclical activity after 19 days of underfeeding and this group was discarded. After 28 days, mature males of Wistar origin were selected at random and placed with the females of the 50 and $62.5 \%$ groups each night for a period of 12 to $15 \mathrm{hr}$ until mating occurred as indicated by spermatozoa in the vaginal smear. The same procedure was adopted with the group on unrestricted feeding and the $75 \%$ group except that, since the oestrous cycles were of the expected duration, males were introduced on the night of the first anticipated oestrus after 28 days. Half the animals in each group, selected at random, were subjected to laparotomy 
to determine the ovulation rate 4 days after the appearance of spermatozoa in the vaginal smear. These animals were anaesthetized with ether and each ovary was exposed through a lateral incision posterior to the last rib. The bursa was opened and the number of corpora lutea counted visually. The incisions were closed and the animals were maintained on the previous dietary regimen.

All animals were killed on the 19th day of pregnancy. The maternal adrenal glands were removed and weighed and the number of foetuses in each uterine horn noted. Statistical analysis throughout was by means of $t$ tests.

Experiment 2. The effect of a short period of unrestricted feeding on ovulation rate and number of viable foetuses at 19 days in the underfed rat

Animals. Eighty female rats from the same colony as Exp. 1 were used. However, they were weaned at 30 days and the proprietary ration was of a slightly different composition from that used in Exp. 1 due to policy changes in the animal breeding unit (Table 1, diet B). As a result of these or other unknown factors, the females at 12 weeks of age had reached puberty earlier than those of Exp. 1, had completed four to five normal cycles and had an average weight of $164 \mathrm{~g}$.

Experimental design. The animals were randomly allocated to three groups of thirty, thirty and twenty animals and maintained in the same environment as in Exp. 1. The twenty-animal group was allowed unrestricted access to food and the other groups were given $75 \%$ of the average daily unrestricted intake with appropriate mineral and vitamin adjustment for 28 days. The introduction of the male before the first expected oestrus was as in Exp. 1. One group of underfed animals was given ENI starting $12 \mathrm{hr}$ before an expected ovulation (feed introduced at 14.00 hours) and returned to a $75 \%$ level of feeding the following morning. If mating did not occur, the rat was kept on restricted intake for a period of at least two more cycles and then given ENI again. Determination of the ovulation rate on half the animals, killing and dissection were carried out as in Exp. 1, with the following modifications. Adrenal weights were not taken. The sex of each foetus was determined by dissection and examination of the reproductive organs. The number of blastocysts which implanted was estimated by counting the deciduomata which persisted in each horn, together with the number of viable foetuses and late resorptions.

Experiment 3. The effect of a short period of unrestricted feeding on ovulation rate as determined by histology in the underfed rat

Eighty female rats similar to those of Exp. 2 were used. Twenty animals allowed unrestricted access to food throughout and two groups of thirty animals (average weight $160 \mathrm{~g}$ ) were each fed $75 \%$ of the daily mean unrestricted intake for 28 days. No animals were allowed contact with a male. After 28 days, one group of thirty animals received ENI for $12 \mathrm{hr}$ before an expected oestrus as indicated by previous vaginal smears. All animals were killed on the 1st day of metoestrus after 28 days of experiment and the ovaries removed. These were fixed in formol saline, processed by wax embedding in a routine manner and serially sectioned at $7 \mu$. Every seventh section was examined for recent ovulations and the total ovulation rate assessed for each animal. 
Experiment 1

\section{RESULTS}

The weight changes and mean cycle lengths for all groups are given in Table 2.

TABLE 2

MEAN BODY WEIGHTS AFTER 28 DAYS, MEAN \% WEIGHT CHANGES AND MEAN CYCLE LENGTHS IN GONTROL AND UNDERFED ANIMALS

\begin{tabular}{|c|c|c|c|}
\hline Group & $\begin{array}{l}\text { Mean final body wt } \\
\quad(g \pm S . E .)\end{array}$ & $\begin{array}{l}\text { Mean \% wt } \\
\text { change }\end{array}$ & $\begin{array}{l}\text { Mean cycle length } \\
\quad(\text { days } \pm \text { S.E. })\end{array}$ \\
\hline $\begin{array}{l}\text { EXPERIMENT 1 } \\
\text { Unrestricted (20) } \\
75 \%(20) \\
62 \cdot 5 \%(20) \\
50 \%(20)\end{array}$ & $\begin{array}{l}150 \cdot 5 \pm 9 \cdot 3 \\
129 \cdot 8 \pm 12 \cdot 7 \\
128 \cdot 9 \pm 12 \cdot 2 \\
104 \cdot 7 \pm 14 \cdot 8\end{array}$ & $\begin{array}{r}+27 \cdot 7 \\
+3 \cdot 3 \\
-7 \cdot 8 \\
-16 \cdot 9\end{array}$ & $\begin{array}{l}4 \cdot 3 \pm 0 \cdot 1 \\
6 \cdot 1 \pm 0 \cdot 3 \\
6 \cdot 2 \pm 0 \cdot 3 \\
7 \cdot 6 \pm 0.5\end{array}$ \\
\hline $\begin{array}{l}\text { EXPERIMENT } 2 \\
\text { Unrestricted (20) } \\
75 \%(60)\end{array}$ & $\begin{array}{l}180 \cdot 8 \pm 11 \cdot 1 \\
153 \cdot 1 \pm 8 \cdot 7\end{array}$ & $\begin{array}{l}+7 \cdot 5 \\
-4.5 \\
\end{array}$ & $\begin{array}{l}4 \cdot 2 \pm 0 \cdot 1 \\
5 \cdot 9 \pm 0 \cdot 4 \\
\end{array}$ \\
\hline $\begin{array}{l}\text { EXPERIMENT } 3 \\
\text { Unrestricted (20) } \\
75 \%(60)\end{array}$ & $\begin{array}{l}156.7 \pm 10.4 \\
143.2 \pm 6.7\end{array}$ & $\begin{array}{l}+9.4 \\
-1.5\end{array}$ & $\begin{array}{l}4 \cdot 3 \pm 0 \cdot 1 \\
5 \cdot 7 \pm 0 \cdot 3\end{array}$ \\
\hline
\end{tabular}

Numbers in parentheses indicate numbers of animals in group or the numbers on which determinations were carried out if these are not the same. This applies to all Tables.

The proportion of animals which were mated and which had viable foetuses at Day 19 of pregnancy, the average ovulation rates and the number of foetuses are shown in Table 3 . There was a decrease in the number of rats which became pregnant with an increase in the degree of restriction of food intake, although there were no significant differences in the number mated in the group on

TABLE 3

THE EFFEGTS OF DIFFERENT FEEDING LEVELS AND A SHORT PERIOD OF REFEEDING ON REPRODUCTIVE BEHAVIOUR

\begin{tabular}{|c|c|c|c|c|}
\hline Group & No. mated & $\begin{array}{c}\text { Ovulation } \\
\text { rate } \pm S . E .\end{array}$ & $\begin{array}{c}\text { No. } \\
\text { pregnant }\end{array}$ & $\begin{array}{l}\text { Mean no. of } \\
\text { foetuses } \pm \text { S.E. }\end{array}$ \\
\hline $\begin{array}{l}\text { EXPERIMENT 1 } \\
\text { Unrestricted (20) } \\
75 \%(20) \\
62 \cdot 5 \%(20) \\
50 \%(20)\end{array}$ & $\begin{array}{r}20 \\
16 \\
19 \\
4\end{array}$ & $\begin{array}{c}12 \cdot 6 \pm 0 \cdot 6(10) \\
9 \cdot 1 \pm 0 \cdot 9(10) \\
9 \cdot 6 \pm 0 \cdot 6(10) \\
8 \cdot 0 \pm 1 \cdot 0(4)\end{array}$ & $\begin{array}{r}18 \\
13 \\
9 \\
1\end{array}$ & $\begin{array}{l}9 \cdot 5 \pm 0 \cdot 4 \\
8 \cdot 0 \pm 0 \cdot 1 \\
7 \cdot 4 \pm 0 \cdot 3 \\
4 \cdot 0\end{array}$ \\
\hline $\begin{array}{l}\text { EXPERTMENT } 2 \\
\text { Unrestricted (20) } \\
75 \%(30) \\
75 \% \text { ENI }(30)\end{array}$ & $\begin{array}{l}20 \\
29 \\
28\end{array}$ & $\begin{array}{l}14.1 \pm 0.6(10) \\
12.8 \pm 0.9(14) \\
15.8 \pm 0.8(13)\end{array}$ & $\begin{array}{l}19 \\
27 \\
21\end{array}$ & $\begin{array}{r}10 \cdot 4 \pm 0 \cdot 3 \\
8 \cdot 9 \pm 0 \cdot 4 \\
7 \cdot 8 \pm 0.4\end{array}$ \\
\hline
\end{tabular}

unrestricted feeding and the $75 \%$ and $62.5 \%$ groups. Fifteen rats in the $50 \%$ group ceased cyclic activity during the 28 days of underfeeding and were not studied further.

There was a reduction in both ovulation rate and the number of viable foetuses at 19 days with increase in dietary restriction. The difference was 
significant $(P<0.01)$ between the unrestricted and $75 \%$ groups and the unrestricted and $62.5 \%$ groups.

The effect of operation on the number of viable foetuses at Day 19 is shown in Table 4. Operation does not seem to affect the number of animals carrying viable foetuses at Day 19. There was, however, a significant reduction $(P<$ 0.05 ) in the number of foetuses in the unrestricted group due to the effects of surgery, with a constant trend for animals previously subjected to laparotomy to have fewer than controls which had no surgical interference.

TABLE 4

THE INFLUENCE OF PREVIOUS LAPAROTOMY ON THE NUMBER OF VIABLE FOETUSES AT 19 DAYS AFTER MATING

\begin{tabular}{l|c|c}
\hline \multirow{2}{*}{ Group } & \multicolumn{2}{|c}{ No. of viable.foetuses \pm S.E. } \\
\cline { 2 - 3 } & Operation & No operation \\
\hline EXPERIMENT 1 & & \\
Unrestricted & $8 \cdot 2 \pm 0 \cdot 6(9)$ & $9 \cdot 9 \pm 0 \cdot 6(9)$ \\
$75 \%$ & $7 \cdot 6 \pm 0 \cdot 4(7)$ & $8 \cdot 5 \pm 0 \cdot 2(6)$ \\
$62 \cdot 5 \%$ & $7 \cdot 0 \pm 0.9(5)$ & $8 \cdot 0 \pm 0 \cdot 4(4)$ \\
\hline EXPERIMENT 2 & & \\
Unrestricted & $10.3 \pm 0.5(10)$ & $10 \cdot 3 \pm 0.5(9)$ \\
$75 \%$ & $8 \cdot 0 \pm 0.5(14)$ & $9 \cdot 8 \pm 0 \cdot 3(13)$ \\
$75 \%$ ENI & $7 \cdot 6 \pm 0.6(13)$ & $8 \cdot 25 \pm 0.4(8)$ \\
\hline
\end{tabular}

Table 5 gives the effect of diet and previous surgery on adrenal weight $/ 100 \mathrm{~g}$ body weight from pregnant animals at slaughter. There were no significant effects of diet or surgery.

TABLE 5

THE EFFECT OF OPERATION AT 4 DAYS POST GOITUM ON MATERNAL ADRENAL WEIGHT AT 19 DAYS

\begin{tabular}{c|c|c}
\hline \multirow{2}{*}{ Group } & \multicolumn{2}{|c}{ Adrenal wt $/ 100 \mathrm{~g}$ body wt $(\mathrm{mg} \pm$ S.E. $)$} \\
\cline { 2 - 3 } & Operation & No operation \\
\hline EXPERIMENT 1 & & \\
Unrestricted & $22.5 \pm 3 \cdot 7$ & $18 \cdot 4 \pm 2.9$ \\
$75 \%$ & $20 \cdot 8 \pm 2 \cdot 3$ & $18.5 \pm 2 \cdot 2$ \\
\hline
\end{tabular}

\section{Experiment 2}

The weight changes for all groups and mean cycle lengths are given in Table 2.

The proportion of animals which mated and those which carried viable foetuses at 19 days, together with ovulation rates and number of foetuses are shown in Table 3 . There were no significant differences between the number of rats which mated or the number pregnant between the groups. There were significantly smaller numbers of viable foetuses at 19 days in both the restricted groups compared to controls $(P<0 \cdot 01)$. 
There were no significant differences in ovulation rates from the freely-fed controls. However, ENI significantly increased the ovulation rate over that of the restricted controls $(P<0.05)$.

The effects of operation on the number of viable foetuses are shown in Table 4. There was a tendency for all groups to have a smaller number of viable foetuses at 19 days in animals subjected to laparotomy compared to controls which had no surgical interference and the difference was significant in the $75 \%$ group $(P<0.01)$.

An estimate of the stage of embryonic mortality, together with the proportion of male and female foetuses, is shown in Table 6 . Whilst there was an increase

TABLE 6

ESTIMATE OF THE STAGE OF EMBRYONIC MORTALITY AND NUMBER OF VIABLE MALE AND FEMALE FOETUSES AT 19 DAYS

\begin{tabular}{l|c|c|c|c}
\hline \multicolumn{1}{c|}{ Group } & $\begin{array}{c}\text { Loss before* } \\
\text { implantation }\end{array}$ & $\begin{array}{c}\text { Loss after } \\
\text { implantation } \pm \text { S.E. }\end{array}$ & $\begin{array}{c}\text { Viable } \\
\text { males }\end{array}$ & $\begin{array}{c}\text { Viable } \\
\text { females }\end{array}$ \\
\hline Unrestricted & $2 \cdot 2(14)$ & $1 \cdot 6 \pm 0.4(14)$ & 98 & 98 \\
$75 \%$ & $3.2(23)$ & $1 \cdot 1 \pm 0.2(23)$ & 110 & 111 \\
$75 \%$ ENI & $6.5(16)$ & $1 \cdot 5 \pm 0.2(16)$ & 71 & 94 \\
\hline
\end{tabular}

* Determined by subtracting the mean litter size plus the mean post-implantation losses from the mean ovulation rate.

in ovulation rate due to ENI over the controls on restricted feeding, there were no significant differences between the number of viable foetuses at 19 days. In the ' $75 \%$ ENI' group, there were fewer males than females, the difference approaching significance $(P<0 \cdot 05)$.

\section{TABLE 7}

\begin{tabular}{|c|c|}
\hline Group & Ovulation rate $\pm S . E$. \\
\hline $\begin{array}{l}\text { EXPERIMENT } 3 \\
\text { Unrestricted (20) } \\
75 \%(30) \\
75 \% \text { ENI }(30)\end{array}$ & $\begin{array}{r}12.5 \pm 0.4 \\
9.3 \pm 0.3 \\
12 \cdot 2 \pm 0.5\end{array}$ \\
\hline
\end{tabular}

\section{Experiment 3}

The results for ovulation rate together with average weight changes are given in Table 7. There were no differences between the $75 \%$ ENI and unrestricted groups but both groups were significantly higher than the $75 \%$ group $(P<0.01)$.

\section{DISCUSSION}

It is apparent that the dietary regimens used in these experiments affect both ovulation rate and the number of viable foetuses at 19 days, both tending to 
decrease with increase in degree of restriction. The differences between animals on unrestricted feeding and the $75 \%$ group were significant despite the relatively mild degree of underfeeding. Below this level, comparisons were complicated by the number of animals which did not become pregnant and attempts to determine the effects of a short period of ENI were carried out using an initial $75 \%$ feed level.

A $75 \%$ feed level used in the rat is not directly comparable to the restriction imposed upon the gilt by Lodge \& Hardy (1968), though the two levels are physiologically similar in that they both allow the respective animal just to maintain body weight with small fluctuations. A comparison between the unrestricted and $75 \%$ groups for Exps. 1 and 2, however, shows differences. The cycle lengths were similar, but the ovulation rate in Exp. 2 was significantly higher. Further, there was no significant difference between animals on unrestricted feeding and the $75 \%$ group in Exp. 2. The rats used in Exp. 2 were $30 \mathrm{~g}$ heavier than those in Exp. 1 and were physiologically more mature, having shown cyclic activity some 2 weeks earlier. The reason for this was not established, but may have been due to a change in diet composition or season. A short period of ENI increased the ovulation rate significantly over restricted controls, but not over unrestricted animals. This is in accord with the suggestion that, in the gilt on restricted feeding, a similar short period of ENI does not cause a superovulation effect but merely restores to normal a depression brought about by a previous low level of feeding (Lodge \& Hardy, 1968). A visual estimate of corpora lutea, the only method available if the animals are required for a subsequent estimate of embryonic and foetal mortality, is not reliable. It was also considered necessary to allow 4 days after mating before operation to ensure that the procedure did not interfere with ova in the Fallopian tube. In consequence, the possibility still existed that the differences were, in fact, due to an increased persistence of corpora lutea rather than ovulation rate. That the effect of ENI is exerted on ovulation rate itself, however, was substantiated by the similar result obtained after histological sectioning in Exp. 3.

It is of interest that, whilst the differences in ovulation rates between groups in Exp. 3 are similar to those in Exp. 2, the actual ovulation rates are lower in Exp. 3, despite the animals being of a similar physiological status in terms of age and weight changes. It is established that the oestrous cycle of the underfed rat can be modified by the presence of the male, the animals coming into oestrus earlier than expected (Gooper \& Haynes, 1967). It is likely that the effect is the result of a nutrition-induced pituitary block in terms of gonadotrophin secretion being removed by the presence of the male. It seems possible that the presence of the male may also influence ovulation rate by a similar mechanism and the absence of a male in Exp. 3 could account for the lower ovulation rates.

The results from foetus-survival studies differ from those described for the pig (Lodge \& Hardy, 1968) since the increase in ovulation rate was not followed by an increase in the number of viable foetuses, the number tending to be less than in control animals. It is suggested that, in the gilt, a uterine mechanism acts to limit litter size to a level characteristic for the species, and the increased embryo death associated with increased embryo numbers appears to be due to 
maternal limitations and not to inherent limitations of the embryo (Bazer, Clawson, Robison \& Ulberg, 1969). A similar situation may exist in the rat, and under the circumstances of restricted feeding, the uterine capacity could, in fact, be depressed below that of unrestricted controls. The trend for more females than males in the ENI group, however, suggests that the conclusion of Bazer et al. (1969) for the gilt may not be strictly applicable in the rat. Nalbandov (1964) reported that in multiparous animals, a greater number of male than female embryos are found immediately after conception but at parturition the sexes are approximately in equal proportions. If this is so, males must be more susceptible to an adverse uterine environment. Therefore, if the nutritional or hormonal status of an ENI animal is such that it can only support a certain number of young, there will be intra-uterine competition between the sexes for survival. There is no difference in the number of implantation sites between the groups, and therefore competition and subsequent loss must occur before implantation.

It is of interest that there is a tendency for animals subjected to operation to have a smaller number of viable foetuses. The lack of any effect of previous laparotomy on either adrenal weight or on the number of animals continuing to carry young is suggestive that the increased mortality is not due to the stress of surgery. Little, Gray \& Lamming (1968) have reported that unilateral resection of a segment of Fallopian tube in the rat after mating causes an increased embryonic loss in the corresponding uterine horn and postulate a local ovary-uterus effect. If such an effect is mediated by way of the Fallopian tube, then damage to the bursa could interfere to some degree and result in an increased embryonic loss.

The management regimen described in this paper was such that $\mathrm{LH}$ release should occur in the majority of rats in the afternoon followed by ovulation some 10 to $12 \mathrm{hr}$ later (Everett, Sawyer \& Markee, 1949). It has been shown that, in a group of underfed female rats maintained in a similar environment, feeding at noon resulted in a greater degree of cyclic activity than feeding at 17.00 hours (Cooper \& Haynes, 1969). The observation that extra feeding just before the expected time of $\mathrm{LH}$ release is associated with a higher ovulation rate suggests that both effects may be closely related. Trie response to an alteration in feeding regimen could either be initiated by a variation in the plasma gonadotrophin levels themselves or by a nutrition-induced modification in the response of the ovary to plasma hormone levels. Further experiments are in progress to clarify the endocrine mechanisms involved.

\section{ACKNOWLEDGMENTS}

The authors are indebted to Mr D. A. MacLean, Miss P. Dillon and Miss G. Heggs for provision and care of the experimental animals.

\section{REFERENCES}

Bazer, F. W., Clawson, A. J., Robison, O. W. \& Ulberg, L. C. (1969) Uterine capacity in gilts. 7. Reprod. Fert. 18, 121.

Bellows, R. A., Meyer, R. K., Hoekstra, W. G. \& Casida, L. E. (1966) Pituitary potency and ovarian activity in rats on two levels of dietary energy. 7 . Anim. Sci. 25, 381. 
COOPER, K. J. \& HAYNEs, N. B. (1967) Modification of the oestrous cycle of the underfed rat associated with the presence of the male. F. Reprod. Fert. 14, 317.

Cooper, K. J. \& Haynes, N. B. (1969) Modification of the oestrous cycle of the underfed rat associated with the time of feeding. 7. Reprod. Fert. 19, 577.

Everett, J. W., Sawyer, C. H. \& Markee, J. E. (1949) A neurogenic timing factor in control of the ovulatory discharge of luteinising hormone in the cyclic rat. Endocrinology, 44, 234.

Heap, F. G., Lodge, G. A. \& Lamming, G. E. (1967) The influence of plane of nutrition in early pregnancy on the survival and development of embryos in the sow. F. Reprod. Fert. 13, 269.

Little, S. L., Gray, A. J. \& Lamming, G. E. (1968) Local effect of the ovary on the uterus of the rat. 7. Endocr. 43, xxxiv.

LODGE, G. A. \& HARDY, B. (1968) The influence of nutrition during oestrus on ovulation rate in the sow. F. Reprod. Fert. 15, 329.

Nalbandov, A. V. (1964) The biology of sex. In: Reproductive Physiology. Freeman, London.

Rigor, E. M., Meyer, R. K., First, N. L. \& CAsida, L. E. (1963) Endocrine differences associated with follicular development and ovulation rate in swine due to bread and energy intake. $\mathcal{F}$. Anim. Sci. 22, 43.

Robertson, G. L., Casida, L. E., Grummer, R. H. \& Chapman, A. B. (1951) Some feeding and management factors affecting age at puberty and related phenomena in Chester White and Poland China gilts. F. Anim. Sci. 10, 841.

Self, H. L., Grummer, R. H. \& Casida, L. E. (1955) The effects of various sequences of full and limited feeding on the reproductive phenomena in Chester White and Poland China gilts. $\mathcal{F}$. Anim. Sci. 14, 573.

Zimmerman, D. R., Self, H. L. \& Casida, L. E. (1957) The effect of flushing for varying lengths of time on the ovulation rate of Chester White, Poland China crossbred gilts. (Abstract). F. Anim. Sci. 16, 1099.

Zimmerman, D. R., Spies, H. G., Self, H. L. \& Casida, L. E. (1960) Ovulation rate in swine as affected by increased energy intake just prior to ovulation. F. Anim. Sci. 19, 295. 